\title{
A Reassess of Various Techniques Applied With Blowfish Algorithm
}

\author{
Shally Nagpal, Suneet Kumar
}

\begin{abstract}
The development height of the web surpasses certain other creation which is assessed by clients and information correspondence. There are distinctive security models following different enciphering systems for the improvement of certified data communication. Various complex cryptographic encryption schemes, which give high condition of security, there always exist vulnerability of these designs increments. Nowadays, the Internet is moving quickly in three of directions for instance, measure, planning power, and programming multi-layered nature making it the snappiest creating development humanity has ever constructed. With the fast improvement of web, one needs to guarantee the delicate data from unapproved get to. Cryptography is expected to be a key part in the field of framework security.
\end{abstract}

Index Terms: Cryptography, Cellular Automata, Elementary Cellular Automata, Internet of Things

\section{INTRODUCTION}

Networks may be personal, together with exclusive a business, or others which might be exposed to free acquire entrance. Network protection is concerned in businesses, corporations, and further types of establishments. Network protection as its name describes: it safeguards the community, protects and examines operations being accomplished. Encryption guarantees the safety by changing the simple content to cryptograph text. [11] [12]. In spite of the fact that this transformation thought is from the past, the method for encryption is still vulnerable to attacks. Some of the popular encryption strategies are caesar's cipher bit-level encryptions, change box, encoding and pivot. These techniques are difficult to execute however goal of encryption is to create coded software which can be utilized to encode secret files including content, pictures and mixed media records in the auxiliary storing devices [2].

1.1 CELLULAR AUTOMATA (CA) Cellular automata (CA) offer various preferences over different techniques as random number generators, for example, algorithmic simplicity and simple equipment execution [1].

\subsubsection{Elementary Cellular Automata}

A framework of basic cellular automata comprises of a one dimensional column of cells, where every cell can be in one of two states, and the standards for the change of a cell depend on the present condition of the cell and its two nearest neighbors. The area along these lines comprises of three cells.
The following is a case of an arrangement of standards for basic cell automata where the two states are called "white" and "dark:"

1. In the event that each of the three cells is white, the cell stays white.

2. In the event that each of the three cells is dark, the cell winds up white.

3. In whatever other case (that is, if there is a blend of high contrast cells in the area), the cell progresses toward becoming (or remains) black [1].

\subsection{CRYPTOGRAPHY}

Cryptography is an investigation of top-secret (crypto) and script (graphy). Cryptography is the skill or specialty which includes the standards and strategies changing communication to encoded form and again changing the encoded communication to its unique frame. Now a day's cryptography is accepted as the investigation of methods and utilizations of safeguarding the truthfulness and validity of exchange of data in troublesome conditions [10].

\section{A. Cryptography Goals \\ - Confidentiality}

Transmitted data should be received by the permitted gathering and not by some other individual.

\section{- Authentication}

The received data should be checked whether it is landing from a permitted individual or an untruthful person.

Integrity

Only the permitted party is allowed to alter the communicated data. No one between the transmitter and collector are allowed for modification the contents.

\section{- Non Repudiation}

Promise that neither the source, nor the receiver of communication has the ability to disagree the conduction.

\section{- Access mechanism}

Only the permitted gatherings can obtain to the assumed data.

\section{B. Fundamental footings}

\section{- Plain Text}

The original message which someone needs to express with some body is considered as Plain Text. For example, Deepak is a man needs to direct "Hello How is life" message to the individual Aman. Here "Hello How is life "is a plain text message.

\section{- Cipher Text}

Futile message which can't be understood by anyone is known as Cipher content. For Instance, "Bke591\#@81vll7!^6\#" is a Cipher Text produced for "Hello How is life ". 


\section{- Encryption}

Encryption is the procedure to convert plain content into encoded content. Encryption involves two main parts first is the encryption scheming and second is the key generation. An encryption scheming suggests the structure which is used as a portion of encryption. At sender side encryption procedure happens.

\section{- Decryption}

Decryption is reverse procedure of encryption which converts cipher content into plain text [4]

\subsubsection{Encryption and Decryption Procedure}

Cryptography involves two processes encryption and decryption. Figure 1.1 displays the encryption and decryption process.

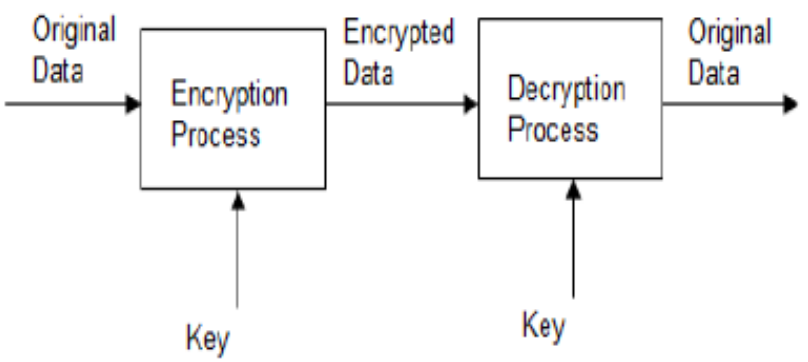

Figure 1.1: Encryption and Decryption procedure [4]

Figure 1.1 shows original data is first encrypted by the sender by using the encryption algorithm and a key. Encrypted data is transmitted to the receiver. After receiving encrypted message on receiver side, decryption is performed by using decryption

\subsubsection{Blowfish}

Blowfish can be efficiently used for encryption and protection of facts and it is a Symmetric Block Cipher (SBC). Blowfish is ideal for securing statistics, takes a variable key usually from 32-48 bits. Blowfish set of rules, iterating a simple encryption feature 16 instances. Blowfish designed in 1993 by Bruce Schneider as a firm, open alternate to present encryption set of rules. [7].

\subsection{IOT Architecture}

IoT design has three layers architecture recognition, system, and application. Recognition layer is responsible to recognize everything in the IoT structure. Recognition layer achieves this by social affair records about every question. Recognition layer holds RFID labels, instruments, cameras, and so forth. Second layer is the system layer and it is the center of IoT. Data assembled by the recognition layer is transmitted by system layer. System layer holds the product and equipment arrangements of web arrange notwithstanding the administration and data focuses. Application layer is the third layer and its main objective is to unite the IoT community requirements and mechanical innovation. Application layer can be thought as the midpoint level among the business advances and in what way it can be organized to fulfill the social requirements [6].

\subsubsection{Safety designed for IoT}

Security of IoT depends on 3- layer design: Figure 1.2shows a safe layered IoT development.

- Physical security: To promise the data accumulation hub in the IoT isn't exhausted, fraud and under control. algorithm and a key.

- Information acquisition security: To retain the collecting of records from listening in, altering, falsification and repetition assaults, which is fundamentally identified with discovering modernism

- Information transmission security: To promise the way of information broadcast, information privacy, honesty, genuineness and convenience of communication, organize safety.

- Information processing security: is data storing, management and entrance to the protection and safekeeping of distributed work out and middleware

- Information security: To promise records safeguard, the comfort of utilization, safekeeping assurance, data leak aversion, and submission safety. [6]

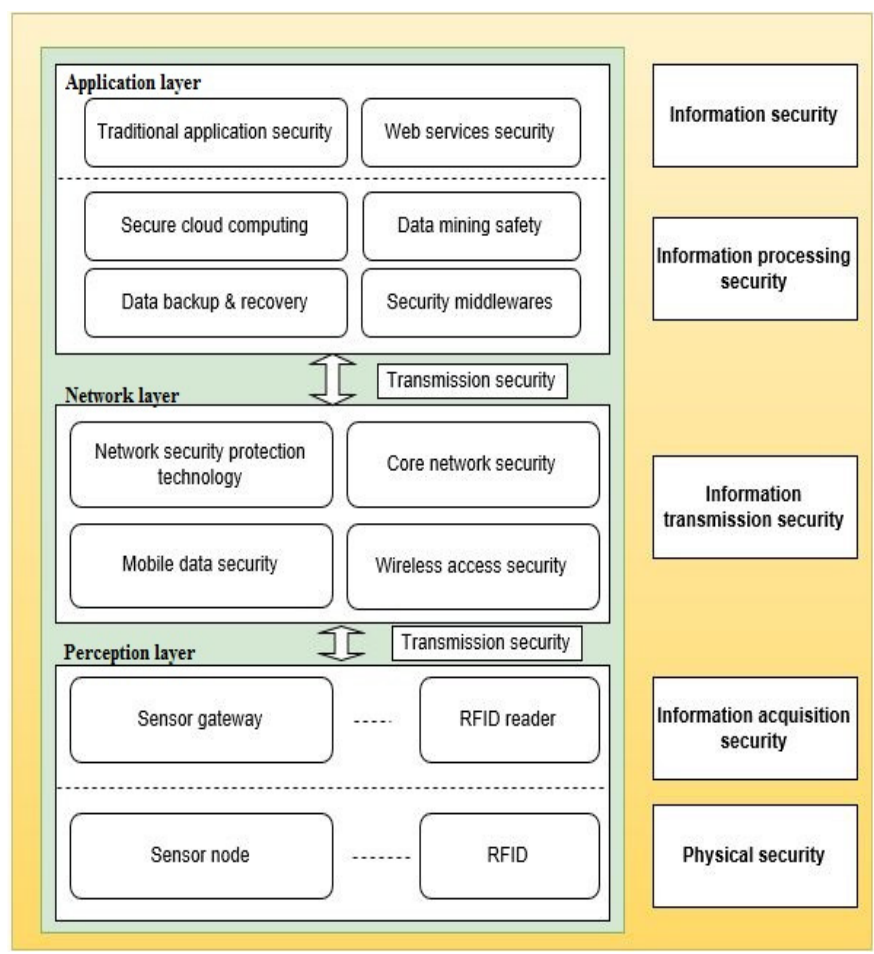

Figure 1.2: 3-Layer Architecture of IOT [6]

\section{LITERATURE REVIEW}

Afaf M. Ali et al. (2011) this wok acquaints another strategy which upgrades the execution of the Blowfish Algorithm. This is achieved by constructing additional configuration for the 16 rounds in the main design by replacing the OR activity with additional offered task. Presented work influences utilization of numerous to release keys. Cellular Automata (CA) is used to create different keys in a basic and compelling mode. Projected method offers top notch encryption, and the structure is exceptionally safe to endeavors of violation the security key.

G. Manikandan et al. (2011) proposed a programming approach that impressively upgrades the safety by ensuing an iterative methodology contingent on transmitter's need. The tests demonstrate that the utilization of iterative methodology upgrades the safety gave by the calculation when contrasted with the non-iterative methodology. 
M. Anand Kumar et al. (2012) this paper chiefly centers around two generally utilized symmetric encryption calculations, for example, Blowfish and Rejindael. These calculations are looked at and execution is assessed. Exploratory outcomes are given to show the execution of these calculations.

SWETA K. PARMAR et al. (2013) it is little bit difficult to choose best cryptography system as there are too many different cryptography systems which can be utilized for securing the information during transmission. Survey finds the blowfish calculation is discovered predominant than alternate calculations. So the proposed look into work is gone for execution of information encryption and decoding calculation for data security.

Christina $L$ et al. (2014) Different calculations and conventions are utilized to secure the information. Throughput and execution time are used to assess the productivity of calculations. Effectiveness of the calculation is influenced by utilizing bigger key size. Focal point of this examination is to divide the four S-boxes into two S-boxes, to improve the speed by enhancing blowfish calculations. The program reproduction outcome gives the better execution and also security.

Manju Suresh et al. (2016) starting with the idea of IoT, design and safety matters, this study divides different safety components for IoT and the criticalness of cryptography techniques for IoT. A proficient cryptographic calculation "Blowfish" is chosen in view of a few examinations. An alteration in Blowfish computation is introduced by changing its Function module 'F'. Encryption time and throughput examination of existing and changed blowfish calculation are considered for comparison.

Avinash M Ghorpade et al. (2016) Cryptography expects a key part in the field of framework security. At the present time various encryption estimations are available to safe the data however these computations eat up package of figuring resources, for instance, battery and CPU time. This paper for the most part focuses on normally used symmetric encryption count (calculation) which is Blowfish computation (calculation). Test outcomes are given to outline the execution of this figuring.

Wenlong Shen et al. (2017) propose a fog-assisted portable group detecting engineering, at that point propose two protection saving group detecting plans for two classes of group detecting applications. The principal plot depends on an added substance homomorphic encryption calculation and permits the administration endorser gather the measurable information without uncovering the individual information from every member. The second plan depends on a bitwise-XOR homomorphic encryption calculation and permits the administration endorser gathers the exact information without know which information is from which member. The projected plans can accomplish k-namelessness security level for every member. Creator likewise gives the execution investigation of the proposed plans.

Hadeal Abdulaziz Al Hamid et al. (2017) the principle center has been assumed to safe social insurance reserved information in the cloud utilizing a haze processing office. A tri-party one round verified key assertion convention has been suggested in light of the bilinear matching cryptography that can create a session key between the members and convey them safely. At long last, the private social insurance information are gotten to and put away safely by executing a fake strategy.

Table 1: Representation Of various Techniques applied on or with Blowfish Algorithm.

\begin{tabular}{|c|c|c|c|}
\hline \multirow{2}{*}{ Algorithm } & \multicolumn{3}{|c|}{ BLOWFISH ALGORITHM } \\
\hline & $\begin{array}{l}\text { Technique } \\
\text { applied on } \\
\text { algorithm }\end{array}$ & Improvement & Year \\
\hline 1 & $\begin{array}{l}\text { Cellular } \\
\text { automata } \\
\text { (CA) based } \\
\text { approach to } \\
\text { project a } \\
\text { symmetric } \\
\text { key } \\
\text { cryptography } \\
\text { scheme }\end{array}$ & $\begin{array}{l}\text { Delivers } \\
\text { extraordinary } \\
\text { class encryption, } \\
\text { and the scheme is } \\
\text { actually strong to } \\
\text { efforts of } \\
\text { violation the } \\
\text { cryptography } \\
\text { key. }\end{array}$ & 2011 \\
\hline 2 & $\begin{array}{l}\text { Programmed } \\
\text { tool which } \\
\text { significantly } \\
\text { improves the } \\
\text { safety by } \\
\text { using } \\
\text { an iterative } \\
\text { methodology }\end{array}$ & $\begin{array}{l}\text { Iterative } \\
\text { methodology } \\
\text { provides better } \\
\text { safety when } \\
\text { related to the } \\
\text { non-iterative } \\
\text { approaches. }\end{array}$ & 2012 \\
\hline 3 & $\begin{array}{l}\text { Rejindael } \\
\text { (AES) } \\
\text { Algorithms }\end{array}$ & $\begin{array}{l}\text { AES has better } \\
\text { performance for } \\
\text { image encryption }\end{array}$ & 2012 \\
\hline 4 & $\begin{array}{l}\text { Modified } \\
\text { blowfish } \\
\text { Encryption } \\
\text { and } \\
\text { Decryption }\end{array}$ & $\begin{array}{l}\text { Modified } \\
\text { Blowfish delivers } \\
\text { great safety and } \\
\text { nobody in } \\
\text { between } \\
\text { transmitter and } \\
\text { receiver can leak } \\
\text { the data. }\end{array}$ & 2013 \\
\hline
\end{tabular}

\begin{tabular}{|l|l|l|l|}
\hline 5 & $\begin{array}{l}\text { Optimized } \\
\text { Blowfish }\end{array}$ & $\begin{array}{l}\text { Optimized } \\
\text { Blowfish } \\
\text { provides }\end{array}$ & 2014 \\
& & reduction of & \\
& & & \\
& & execution time & \\
& & and improvement \\
& & \\
& & in 0.24 bytes/ms & \\
& & compared to & \\
& & original & \\
& & algorithms. & \\
& &
\end{tabular}




\begin{tabular}{|l|l|l|l|}
\hline 6 & $\begin{array}{l}\text { Altering } \\
\text { Function } \\
\text { module ' } F \text { ' in } \\
\text { Blowfish } \\
\text { Algorithm }\end{array}$ & $\begin{array}{l}\text { The modified } \\
\text { blowfish } \\
\text { algorithm } \\
\text { provides } \\
\text { improvement in } \\
\text { encryption time } \\
\text { by 16.9\% and } \\
\text { throughput by } \\
18.7 \% \text {. }\end{array}$ & \\
& & & \\
\hline
\end{tabular}

\section{CONCLUSION}

For many applications Blowfish is currently assumed to be insecure. So it turns out to be essential to enhance this procedure through innovative planes of safety to mark it relevant as well as can be contingent upon in every regular correspondence channel. Cryptanalysis of streamlined Blowfish algorithm is examined and this algorithm can be used with other information compose, for example, content record, sound and video. By dissecting diverse security issues related with IoT, significant offer of the similar are happening in the in safe channel which associates distinctive IoT hubs and WSN hubs. For giving data communication safety in the system level, encryption methods can be utilized. Out of all the encryption techniques, Blowfish calculation is the best as far as implementation time, memory utilization, output, control utilization, safety and accordingly appropriate for IoT

\section{REFERENCES}

1. Afaf M. Ali Al-Neaimi, Rehab F. Hassan, "New Approach for Modifying Blowfish Algorithm by Using Multiple Keys”, International Journal of Computer Science and Network Security, VOL.11 No.3, March 2011, pp.21-26.

2. G. Manikandan, N. Sairam and M. Kamarasan, "A New Approach for Improving Data Security using Iterative Blowfish Algorithm", Research Journal of Applied Sciences, Engineering And Technology 4(6): pp. 603-607, 2012

3. M. Anand Kumar and Dr.S.Karthikeyan, "Investigating the Efficiency of Blowfish and Rejindael (AES) Algorithms", I. J. Computer Network and Information Security, 2012, 2, pp.22-2.

4. SWETA K. PARMAR, K.C. DAVE, "IMPLEMENTATION OF DATA ENCRYPTION AND DECRYPTION ALGORITHM FOR INFORMATION SECURITY", International Journal of Advances in Science Engineering and Technology, Volume- 1, Issue- 2, Oct-2013,pp.7-10.

5. Christina L, Joe Irudayaraj V S, "Optimized Blowfish Encryption Technique", International Journal of Innovative Research in Computer and Communication Engineering, Vol. 2, Issue 7, July 2014, pp.5009-5015.

6. Manju Suresh , Neema M, "Hardware implementation of blowfish algorithm for the secure data transmission in Internet of Things", Global Colloquium in Recent Advancement and Effectual Researches in Engineering, Science and Technology, 2016 ,pp.248 - 255.

7. Avinash $\mathrm{M}$ Ghorpade, Harshavardhan Talwar, "The Blowfish Algorithm Simplified", International Journal of Advanced Research in Electrical, Electronics and Instrumentation Engineering, Vol. 5, Issue 4, April 2016, pp.3343-3351.

8. Wenlong Shen, Bo Yin, Yu Cheng, Xianghui Cao and Qing Li," Privacy-Preserving Mobile Crowd Sensing for Big Data Applications", IEEE ICC ,2017,pp.1-6.

9. Hadeal Abdulaziz Al Hamid, Sk Md Mizanur Rahman, M. Shamim Hossain, Ahmad Almogren, Atif Alamri, "A Security Model for Preserving the Privacy of Medical Big Data in a Healthcare Cloud Using a Fog Computing Facility with Pairing-Based Cryptography”, IEEE ACCESS. VOL.XXX, NO.XX, 2017, pp.1-16.

10. Gurvinder Singh Sandhu, Vinay Verma, "Comparing Popular Symmetric Key Algorithms Using Various Performance Metrics",
International Journal of Advance Research in Computer Science and Management Studies Volume 1, Issue 7, December 2013

11. KritikaAcharya, ManishaSajwan, Sanjay Bhargava, "Analysis of Cryptographic Algorithms for Network Security", International Journal of Computer Applications Technology and Research Volume 3- Issue 2, 2014

12. Mohammad Soltani, "A New Secure Image Encryption Algorithm using Logical and Visual Cryptography Algorithms and based on Symmetric Key Encryption Journal of Basic and Applied Scientific Research, 3(6)1193-1201, 2013

\section{AUTHORS PROFILE}

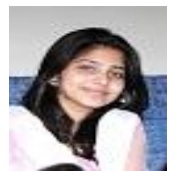

Shally Nagpal is research scholar in CSE Deptt in MMDU (Ambala). She has completed her M.Tech from BPSMV Khanpur Kalan in year 2017. She has two years of educational expertise. She has completed his B.Tech from Maharishi Markandeshwar College Of Engineering MMDU(Ambala) In 2011. She has published three paper one in international journal, one in international Conference and one in national conference. Her research area is security in Big Data.She has attended many workshops.

E-Mail id -shally.ngpl@gmail.com

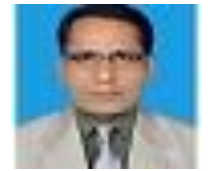

Suneet Kumar obtained his Doctorate degree in computer science and engineering in 2012. He holdsMaster's degree in computer science and engineering from Bhagwant university, Ajmer ,Rajasthan passed in 2006. His totalexperience is 16 year, presently, working as Associate Professor(CSE) in MMEC ,Maharishi Markandeshwar Deemed To Be University since Feb-2015. He has presented 5 papers in international /national conferences and published 17 paper in international journals. He has conducted various international ,national conferences,seminars and workshops also.

E-mail: suneetcit81@gmail.com 